\title{
Psychiatric Morbidity among the General Hospital Medical Patients in Kuwait: Characteristics of Psychiatric Patients
}

\author{
M.A. Zahid M.A. Razik M.M.A. Motaal \\ General Medical Out-patient Clinic, Mubarak Al-Kabeer Hospital, Kuwait
}

\section{Key Words}

Psychiatric disorder · Morbidity · General

hospital · Medical out-patients

\begin{abstract}
Objectives: A considerable number of medical out-patients seen in a general hospital are known to suffer from psychiatric rather than/ in addition to the physical disorder. Moreover, a substantial number of such patients, passing undetected by the physicians, end up being physically examined and investigated, at times far too extensively. This study was aimed at determining the prevalence of such patients in a general hospital in Kuwait. Methods: The sample consisted of 100 new medical out-patient clinic attenders. Each patient was administered a semi-structured interview. The items of the interview were derived from the Present State Examination, and the 10th revision of the International Classification of Diseases was used to assign psychiatric diagnoses. Results: Fifty-one out
\end{abstract}

\begin{tabular}{ll}
\hline KARGER & (1) 1999 S. Karger AG, Basel \\
Fax +4161306 1234 & 1011-7571/99/0084-0301\$17.50/0 \\
$\begin{array}{l}\text { E-Mail karger@karger.ch } \\
\text { www.karger.com }\end{array}$ & $\begin{array}{l}\text { Accessible online at: } \\
\text { www.karger.com/journals/mpp }\end{array}$
\end{tabular}

of the 100 patients suffered from psychiatric disorders. In only 5 cases was the disorder recognized. Psychiatric disorders were commoner in females and were not related to the nature of the physical disorders. Conclusions: Inclusion of some screening questions about mood disorders in the standard medical interview may help detect some of the psychiatric patients presenting in the general medical out-patient clinics. In addition, periodic clinical meetings between psychiatrists and physicians may enhance physicians' awareness of the potential psychiatric morbidity amongst the medical out-patients.

Copyright @ 1999 S. Karger AG, Basel

\section{Introduction}

Various community surveys have reported rates of psychiatric morbidity to vary from 8.7 to $31.5 \%[1,2]$. This variation has largely resulted from different screening instruments and diagnostic criteria used by different work-

Dr. M.A. Zahid

Department of Psychiatry, Faculty of Medicine

Kuwait University, PO Box 24923

13110 Safat (Kuwait)

Tel. +965 5312300 Ext. 6321, +965 5330467, Fax +965 5338904 
ers. Using highly sophisticated diagnostic interviews and applying stringent diagnostic criteria, two recent large community surveys in the US have shown that as many as $20-30 \%$ of the adult population suffer from one or more psychiatric disorders [3, 4]. The psychiatric patients seen in psychiatric hospitals or clinics constitute only about $5-10 \%$ of the total psychiatric morbidity, while the remaining $90-95 \%$ are treated by the general practitioners, physicians and surgeons [5]. Similarly, a considerable proportion of patients seen in the medical settings are known to suffer from psychiatric rather than or in addition to a physical disorder [6]. Surprisingly, as many as one third, and according to some estimates, up to one half of this psychiatric morbidity passes undetected [7]. The investigations being expensive and time consuming, these patients draw more than their share and pose undue burden on the health services. Identification of these psychiatric patients has important clinical implications. Saving the patients from repeated physical examinations, this may also help alleviate their suffering through timely provision of psychiatric intervention.

Rates of psychiatric morbidity among medical out-patients vary depending upon the diagnostic criteria used and the population of the patients studied. Jacobsson [8] studied 465 out-patients in a general hospital and found $18 \%$ to be suffering from neurotic conditions. Diagnostic criteria and interview schedule were, however, not specified. Ruiz and Silva [9] used DSM III-R criteria and reported that $55 \%$ of their out-patients suffered from psychiatric disorders. Barskly et al. [10] found that $46 \%$ of their patients with palpitations suffered from psychiatric disorders. There seems to be a general consensus that as many as $50 \%$ of the general medical outpatients may be suffering from psychiatric rather than or in addition to the physical disorders. We decided to investigate the preva- lence of psychiatric morbidity among the medical out-patient clinic attenders in a general hospital.

Kuwait is an Arab country located on the north-western tip of the Arabian Gulf. Because of its oil resources, it has one of the highest per capita incomes in the world. It has a population of about 1.8 million, of which Kuwaitis represent 40\%, the rest being Arabs $38 \%$, Asians $21 \%$, and Europeans and Americans $1 \%$ [11]. The free-of-charge national health care system consists of 6 regional general hospitals and 114 Primary Health Care Centres (similar to general practitioner surgeries), uniformly distributed throughout the country [12]. The hospitals operate on a referral system, drawing most of their outpatients from the primary health clinics which are manned by general practitioners. The study was conducted in Mubarak Al-Kabir Hospital, a regional general teaching hospital attached to the only medical school in $\mathrm{Ku}$ wait. The hospital has more than 350 beds; serves a catchment area of about 350,000; and runs an out-patient clinic 5 days a week [12].

\section{Aims and Objectives}

The aims of the study were to (1) determine the proportion of medical out-patients suffering from psychiatric disorders and (2) see if the presence of psychiatric morbidity was related to age, sex, ethnicity or any particular kind of physical disorders.

\section{Methods}

\section{Sampling}

The nursing staff, stationed in the out-patient clinic and concerned with registration of new patients, was requested to refer all the consenting patients for psychiatric assessment. The patients were assessed on 2 different weekdays, spread evenly throughout the 18- 
Table 1. Characteristics of the sample studied

\begin{tabular}{lcc}
\hline & Count & $\%$ \\
\hline Age & & \\
$\quad<25$ years & 20 & 20 \\
25-50 years & 65 & 65 \\
$\quad$ 51+ years & 16 & 15 \\
\hline Sex & & \\
$\quad$ Male & 55 & 55 \\
$\quad$ Female & 45 & 45 \\
\hline Nationality 1 & \\
$\quad$ Arabs & & \\
$\quad$ Non-Arabs & 67 & 67 \\
\hline Education ${ }^{2}$ & 32 & 32 \\
$\quad$ No education & 11 & 11.60 \\
$\quad$ 1-5 years & 22 & 23.20 \\
$\quad$ 6-12 years & 40 & 42.10 \\
$\quad$ 13+ years & 22 & 23.20 \\
\hline Nationality of 1 patient not known. \\
2 Information missing about 5 patients. \\
\hline
\end{tabular}

1 Nationality of 1 patient not known. ric conditions described in the medical outpatient settings [8-10]. Each obligatory question was followed by supplementary questions in order to clarify the symptom or to elicit additional information required to make the diagnoses, which were assigned manually.

\section{Measures}

The 10th revision of the International Classification of Diseases (ICD-10), Diagnostic Criteria for Research [14], was used to assign psychiatric diagnoses. The physical diagnoses recorded were the same as assigned by the treating clinician.

\section{Statistical Analysis}

The data were analysed on SPSS. Comparison of the psychiatric versus non-psychiatric group was made to see if the two groups differed in relation to age, gender, education and ethnicity. For categorical variables including age, gender and ethnicity, bivariate analysis was used and the significance ascertained through the $\chi^{2}$ test. For education, a continuous variable, ANOVA was used and $F$ statistics calculated to see the significance level.

\section{Result}

The sample consisted of 100 medical outweek study period from December 1995 to April 1996. Circumstances surrounding the recruitment of patients did not permit psychiatric evaluation of a number of possibly consenting patients nor the randomisation of the patients. The general medical out-patient clinics in Kuwait are overcrowded, drawing 50-100 patients daily. We managed to include about $5-7 \%$ of all new out-patient clinic attenders.

\section{Procedures}

Prior to consultation with the respective physician, each patient was administered a semi-structured psychiatric interview by the trained psychiatrists (M.A.R. and M.A.M.). The physicians' diagnoses, both physical and/or psychiatric, as recorded in the case-notes, were subsequently retrieved. In addition, general information was recorded about the age, sex, education and ethnic origin of the patients.

\section{Instruments}

The semi-structured interview was based on obligatory questions from the Present State Examination [13]. The questions related to 'Neurotic, stress-related, and somatoform disorders', the commonest psychiat-

Psychiatric Morbidity among Medical Patients patients. Age ranged from 12 to 86 (mean = 37.13 years, $\mathrm{SD}=13.70)$. There were 55 males and 45 females (table 1).

Just over two-thirds were Arabs and the rest represented seven different nationalities including Iran, Turkey, Indo-Pak subcontinent, Phillipines and Korea. The number of illiterate patients was $11.6 \%$, and $62 \%$ had received 12 or more years schooling.

\section{Psychiatric Diagnoses}

Fifty patients fulfilled the ICD-10 diagnostic criteria. Generalized anxiety disorder, mild depressive episode and mixed anxiety and depressive disorder accounted for more than two thirds of the psychiatric cases (table 2).

In only 5 patients did the examining physician recognize that the patient had psychiatric 
Table 2. Psychiatric diagnoses of the patients

\begin{tabular}{|c|c|c|c|}
\hline Valid & Frequency & $\%$ & Cumulative, $\%$ \\
\hline None & 49 & 49.0 & 49.0 \\
\hline Generalized anxiety disorder & $17(33 \%)$ & 17.0 & 66.0 \\
\hline Mild depressive episode & $9(18 \%)$ & 9.0 & 75.0 \\
\hline Mixed anxiety and depression & $8(16 \%)$ & 8.0 & 83.0 \\
\hline Somatisation disorder & $5(10 \%)$ & 5.0 & 88.0 \\
\hline Hypochondriacal disorder & $2(4 \%)$ & 2.0 & 90.0 \\
\hline Somatoform autonomic dyfunction & $2(4 \%)$ & 2.0 & 92.0 \\
\hline Bipolar affective disorder & $2(4 \%)$ & 2.0 & 94.0 \\
\hline Phobic anxiety disorder & $1(2 \%)$ & 1.0 & 95.0 \\
\hline Panic disorder & $1(2 \%)$ & 1.0 & 96.0 \\
\hline Acute stress reaction & $1 \quad(2 \%)$ & 1.0 & 97.0 \\
\hline Adjustment disorder & $1(2 \%)$ & 1.0 & 98.0 \\
\hline Somatoform pain disorder & $1(2 \%)$ & 1.0 & 99.0 \\
\hline Senile dementia & $1(2 \%)$ & 1.0 & 100.0 \\
\hline Total & 100 & 100.0 & 100.0 \\
\hline
\end{tabular}

disorder. The disorders suggested were anxiety once, anxiety and depression once and neurotic thrice.

\section{Medical Diagnoses and Psychiatric}

\section{Morbidity}

Overall, 32 different medical diagnoses were assigned by the treating clinicians. Out of them, $36 \%$ related to the gastro-intestinal tract (GIT) and $28 \%$ to the cardiovascular system (CVS; table 3).

The commonest diagnoses used, in the order of frequency, were irritable bowel syndrome $(n=13)$, peptic ulcer $(n=12)$, hypertension $(\mathrm{n}=11)$ and gastritis $(\mathrm{n}=9)$. In 5 patients the diagnoses were limited to the presenting complaint only, i.e. chest pain, backache, chest infection, leg pain, indigestion. Out of 36 patients presenting with GIT symptoms, $19(53 \%)$ received one or another kind of psychiatric diagnoses while $14(50 \%)$ out of 28 patients with CVS symptoms were found to have concomitant psychiatric morbidity.

304

Med Principles Pract 1999;8:301-308
Psychiatric versus Non-Psychiatric Group

The psychiatric group of patients was compared with the non-psychiatric group in terms of age, gender, education and ethnicity (table 3 ). There was a significantly higher number $(p>0.015)$ of females in the psychiatric group (table 4).

The age group 26-50 was over-represented in the psychiatric patients, but the number failed to reach statistical significance $(p>$ 0.078). There were no differences between the groups in relation to education.

\section{Discussion}

Our findings are consistent with the earlier reports that as many as one half of the medical out-patients suffer from psychiatric disorders. However, only a few of our psychiatric patients were recognised by the physicians. This can be explained in a number of ways. Firstly, the predominance of somatic over behavioural and emotional presentation of psychiatric 
Table 3. Physical diagnoses with and without psychiatric co-morbidity

Table 4. Comparison of psychiatric versus non-psychiatric patients

Psychiatric Morbidity among Medical Patients

\begin{tabular}{llll}
\hline Physical diagnoses & \multicolumn{2}{l}{ Psychiatric diagnoses } & Total \\
\cline { 2 - 3 } & yes & no & \\
\hline Irritable bowel syndrome & 8 & 5 & 13 \\
Duodenal ulcer & 5 & 7 & 12 \\
Hypertension & 6 & 5 & 11 \\
Gastritis & 5 & 4 & 9 \\
Diabetes mellitus & 2 & 4 & 6 \\
Hypothyroidism & 3 & 2 & 5 \\
Mitral valve prolapse & 2 & 2 & 4 \\
Renal artery occlusion & 2 & 2 & 4 \\
Ischaemic heart disease & 1 & 3 & 4 \\
Obesity & 3 & - & 3 \\
Arthritis & 2 & 1 & 3 \\
Atrial fibrillation & - & 2 & 2 \\
Hepatitis & 2 & - & 2 \\
Oesophagitis & 1 & 1 & 2 \\
Gout & 1 & 1 & 2 \\
Epilepsy & - & 2 & 2 \\
Miscellaneous & 8 & 8 & 16 \\
\hline
\end{tabular}

\begin{tabular}{lcccc}
\hline & Psych. & $\begin{array}{c}\text { Non- } \\
\text { psych. }\end{array}$ & Total & Significance \\
\hline Age & & & & \\
$\quad \leq 25$ years & 6 & 14 & 20 & \\
$\quad 26-50$ years & 38 & 27 & 65 & $\mathrm{p}<0.078^{1}$ \\
$\quad 51+$ years & 7 & 8 & 15 & \\
\hline Sex & & & & \\
$\quad$ Male & 22 & 33 & 55 & $\mathrm{p}>0.015^{1}$ \\
$\quad$ Female & 29 & 16 & 45 & $\mathrm{p}>0.388^{1}$ \\
\hline Ethnicity & & & & \\
$\quad$ Arabs & 35 & 32 & 67 & $\mathrm{p}>0.079^{2}$ \\
$\quad$ Non-Arabs & 15 & 17 & 32 & \\
\hline Education & & & & \\
$\quad$ Mean (years) & 7.83 & 9.65 & & \\
$\quad$ SD & 5.03 & 4.99 & & \\
\hline $1 \quad \chi^{2}$ Test. & & & & \\
$\quad$ ANOVA. & & &
\end{tabular}


disorders in the Arab communities has been well documented [15]. Some patients may be expressing emotional problems in bodily symptoms (somatising), thereby restricting further inquiries into the possible underlying emotional disturbances. Secondly, the Arab language tends to be over-emphatic and hyperbolic where emotivity takes precedence over rationality [15]. Some physicians, not familiar with the cultural correlates of linguistic expression, may find it difficult to discern the underlying psychopathology in psychiatric patients presenting with physical symptoms.

It must be said here that the patients were assessed on a single occasion, and the evolution of the symptoms in relation to the possible underlying physical illness may have compounded their psychiatric symptomatology. Moreover, the patients were examined prior to the consultation with their respective physicians and, therefore, were perhaps 'apprehensive' about the possible outcome of their 'encounter' with the physician. This might have inflated the psychological component of their symptomatology especially the accompanying anxiety state to an extent of them receiving a psychiatric rather than or in addition to the physical diagnosis. Some bias in favour of a psychiatric nature of the disorders is therefore possible. However, our patients were administered a semi-structured interview which, contrary to the questionnairebased assessment, was expected to yield relatively modest prevalence rates [16]. In addition, the relatively stringent diagnostic criteria used, namely ICD-10, minimizes this bias.

\section{The Psychiatric and Physical Diagnoses}

More than four fifths of our psychiatric patients suffered from mood disorders, and another $10 \%$ had somatisation disorder. Similar findings have been reported in the earlier studies [8-10]. The wider range of medical diagnoses reflects the mixed nature of the patients in our general medical out-patient clinic, and a number of them were channeled onward to the specialty clinics like cardiology, gastro-enterology, respiratory diseases etc. for tertiary care. High rates of psychiatric disorders have been documented in patients with GIT and CVS symptoms. Analysing data from the Epidemiologic Catchment Area (ECA) project, North et al. [17] found that more than half $(51 \%)$ of the men and nearly half $(45 \%)$ of the women reporting two or more GIT symptoms met lifetime criteria for a psychiatric diagnosis. Similarly, Barsky et al. [10] found that $46 \%$ of their patients with CVS symptoms suffered from psychiatric disorders. Our results are more or less consistent with these findings. Nineteen (53\%) out of 36 of our patients presenting with GIT symptoms and 14 (50\%) out of 28 with CVS symptoms met the ICD-10 criteria for one or another kind of psychiatric disorder. Co-existence of psychiatric morbidity with GIT and CVS illnesses underlines the usefulness of communication between psychiatrists and cardiologists and gastroenterologists, regarding the implications for the management of these disorders.

\section{Comparison of Psychiatric and Organic Patients}

The socio-demographic characteristics of psychiatric patients presenting in the medical clinics have been described in several studies. It has been suggested that people of lower social class and poorer education tend to somatise their emotional distress [18]. Mumford et al. [19] found no such correlation and in fact their psychiatric group tended to be more educated than the organic group of patients. In our study there were no significant differences between the two groups in relation to age and education, but the psychiatric 
group had a higher number of females. In view of the relatively smaller size of our sample, the findings may just be coincidental. Another possible explanation may be the fact that the psychiatric morbidity detected by our semi-structured interview, is known to be at least one and a half times higher in females [1].

The present study confirms findings from several previous studies that, regardless of the presence of concomitant physical illness, as many as half of the medical out-patients may be suffering from psychiatric disorders, and that physicians are poor at recognizing them. Numerous studies have reported that psychiatric disorders not only lead to over-utilisation of medical services [20], but also adversely affect the prognosis in the medically ill patients [21]. If identified early, these patients may benefit from timely provision of psychiatric help. Moreover, picking out potential over-utilisers of health services can have important cost effective implications for the health care providers. It must, however, be said here that despite repeated findings, many of which have been published in internal medical journals, the rate of recognition of psychiatric disorders by the physicians remains disappointingly poor. Inclusion of some screening questions about mood disorders in the standard medical interview may help detect some of these patients. In addition, periodic clinical meetings between psychiatrists and physicians and, as remarked earlier by some workers [9], a better psychiatric training of clinicians in general, and primary medical care clinicians in particular, may help.

\section{Acknowledgment}

This study was funded by the Kuwait University via Grant No. MDQ 283.

\section{References}

1 Dean C, Suretees PG, Sashidharan SP: Comparison of research diagnostic systems in an Edinburgh community sample. Br J Psychiatry 1983;142:247-256.

2 Goldberg DP, Huxley P: Common mental disorders. A bio-social model. London, Tavistock/Routledge, 1992.

3 Regier DA, Narrow WE, Rae DS, Manderschied RW, Locke BZ, Goodwin FK: The de facto US mental and addictive disorders service system: Epidemiologic Catchment Area prospective 1-year prevalence rates of disorders and services. Arch Gen Psychiatry 1993;50:85-94.

Psychiatric Morbidity among Medical Patients
4 Kessler RC, McGonagle KA, Zhao S, Nelson CB, Hughes M, Eshleman $\mathrm{S}$, Wittchen HU, Kendler KS: Lifetime and 12-month prevalence of DSM-III-R psychiatric disorders in the United States: Results from the National Comorbidity Survey. Arch Gen Psychiatry 1994;51:8-19.

5 Shepherd M, Cooper B, Brown AC, Kalton GW: Psychiatric illness in general practice. Oxford, Oxford University Press, 1966.

6 Goldberg D, Privett M, Ustan B, Simon G, Linden M: The effects of detection and treatment on the outcome of major depression in primary care: A naturalistic study in 15 cities. Br J Gen Pract 1998;48: 1840-1844.
7 Brody DS: Physician recognition of behavioural, psychological and social aspects of medical care. Arch Intern Med 1980;140:1286-1289.

8 Jacobsson L: Psychiatric morbidity and psychosocial background in an outpatient population of a general hospital in western Ethiopia. Acta Psychiatr Scand 1985; 71:417-426.

9 Ruiz A, Silva H: Prevalence of psychiatric disorders in an outpatient service of general medicine. Rev Med Chile 1990;118:339-345.

10 Barsky AJ, Cleary PD, Coeytaux RR, Ruskin JN: Psychiatric disorders in medical outpatients complaining of palpitations. J Gen Intern Med 1994;9:306-313. 
11 Central Statistical Office: Annual Statistical Abstract. Kuwait, Central Statistical Office, Ministry of Planning, 1998.

12 Ministry of Public Health: Vital and Health Statistics. Kuwait, Ministry of Public Health, 1993.

13 Wing JK, Cooper JE, Sartorius N: The measurement and classification of psychiatric symptoms. London, Cambridge University Press, 1974.

14 World Health Organisation: International Classification of Diseases, Research Diagnostic Criteria, rev 10. Geneva, WHO, 1992.

15 El-Islam MF: Arab cultural psychiatry. Transcult Psych Res Rev 1982a 19:5-24.
16 Mumford DB: Somatic sensations and psychological distress among students in Britain and Pakistan. Soc Psychiatry Psychiatr Epidemiol 1989;24:321-326.

17 North CS, Alpers DH, Thompson SJ, Spitznagel EL: Gastrointestinal symptoms and psychiatric disorders in the general population. Findings from NIMH Epidemiologic Catchment Area Project. Dig Dis Sci 1996;41:633-640.

18 Crandell DL, Dohrenwend BP: Some relations among psychiatric symptoms, organic illness and social class. Am J Psychiatry 1967;123: 1527-1538.
19 Mumford DB, Tareen IAK, Bhatti MR, Bajwa MAZ, Pervez T, Ayub $\mathrm{M}$ : An investigation of 'functional' somatic symptoms among patients attending hospital medical clinics in Pakistan II. Using somatic symptoms to identify patients with psychiatric disorders. J Psychosom Res 1991;35,2:3;257-264.

20 Fink P: Mental illness and admission to general hospital. Acta Psychiatr Scand 1990;82:458-462.

21 Vogt T, Pope C, Mulloly J, Hollis J: Mental health status as a predictor of morbidity and mortality: A 15year follow-up of members of a health maintenance organisation. Am J Public Health 1994;84:227231. 